\title{
1. Introduction: the need for a new paradigm of mediation ethics
}

Mediation is becoming more and more prominent internationally as a key form of dispute resolution for legal and other disputes. In some jurisdictions, participating in mediation is a compulsory pre-filing requirement in particular kinds of legal matters. ${ }^{1}$ Many benefits have been claimed for mediation as a mode of resolving disputes, including its informality, flexibility, less adversarial nature, and focus on the parties and their interests. ${ }^{2}$ The growth of this form of dispute resolution has produced a considerable academic literature, but the theoretical foundations and conceptual framework of mediation ethics have been relatively neglected. ${ }^{3}$

Discussions of mediation ethics have traditionally focused heavily on the role of mediator neutrality and impartiality in supporting the achievement of party self-determination and a fair process. An ethical mediator, on this view, is neutral and/or impartial because taking a neutral, impartial stance makes

\footnotetext{
1 See, for example, in Australia the Family Law Act 1975 (Cth) s 60I-K. For discussion, see Vicki Waye, 'Mandatory Mediation in Australia's Civil Justice System' (2016) 45 Common Law World Review 214; Virginia Vilches Such, Alain Laurent Verbeke and Carrie Menkel-Meadow, 'Mandatory Workplace Mediation' in Katalien Bollen, Martin Euwema and Lourdes Munduate (eds), Advancing Workplace Mediation Through Integration of Theory and Practice (Springer, 2016); Nancy H Rogers, 'Mediation and the Law' in Beatrice Blohorn-Brenneur et al (eds), How Mediation Works: Theory, Research, and Practice (Emerald Publishing, 2017); Randall C Jenkins et al, 'Mandatory Pre-Suit Mediation for Medical Malpractice: Eight-Year Results and Future Innovations' (2017) 35 Conflict Resolution Quarterly 73.

2 See generally Michael King, Arie Freiberg and Becky Batagol, Non-Adversarial Justice (Federation Press, 2nd ed, 2014) 104-6; Laurence Boulle and Rachael Field, Australian Dispute Resolution: Law and Practice (LexisNexis, 2017) chs 2 and 7; Laurence Boulle and Rachael Field, Mediation in Australia (LexisNexis, 2018).

3 There are, of course, some exceptions. See, for example, Michael Lang and Alison Taylor, The Making of a Mediator: Developing Artistry in Practice (Jossey-Bass, 2000); Bernard Mayer, Beyond Neutrality: Confronting the Crisis in Conflict Resolution (Jossey-Bass, 2002); Bobette Wolski, Skills Ethics \& Values for Legal Practice (Lawbook Co, 2nd ed, 2008); Ellen Waldman, Mediation Ethics: Cases and Commentaries (John Wiley \& Sons, 2011); Omer Shapira, A Theory of Mediators' Ethics (Cambridge University Press, 2016); Margaret Castles and Anne Hewitt, Dispute Resolution and Ethics (Lawbook Co, 3rd ed, 2018).
} 
party self-determination possible; non-neutral interventions and partial behaviour on the part of the mediator are assumed to undermine and contradict party self-determination. ${ }^{4}$ However, this focus has been criticised in recent decades for being unrealistic as it overlooks the complexity of party communications and negotiations in mediation. In particular, it ignores important issues such as the power of the mediator, as well as the need to address power imbalances between the parties. There is now a significant body of academic literature questioning whether mediators can ever truly be neutral or impartial and asking whether these concepts serve to mask the mediator's real influence. ${ }^{5}$ Furthermore, the possibility of achieving self-determined outcomes for parties - the characteristic that makes mediation special and different from other varieties of dispute resolution ${ }^{6}$ - may require a more proactive and interventionist role than the ethics of neutrality and impartiality theoretically or practically allow. ${ }^{7}$

While the central place of neutrality and impartiality in mediation ethics has increasingly been questioned, there is, however, a lack of consensus on how to conceptualise mediation ethics without these ideas. The question is pressing given the increasing reliance on mediation by domestic and international legal systems and a growing perception of mediation as an emerging profession. ${ }^{8}$ A traditional hallmark of a profession is its ability to self-regulate by applying

4 See, for example, William A Donohue, 'Communicative Competence in Mediators' in Kenneth Kressel and Dean C Pruitt (eds), Mediation Research: The Process and Effectiveness of Third-Party Intervention (Jossey-Bass, 1989) 322-43; Christopher Moore, The Mediation Process: Practical Strategies for Resolving Conflict (Jossey-Bass, 1996) 14; Jay Folberg and Alison Taylor, Mediation: A Comprehensive Guide to Resolving Conflict Without Litigation (Jossey-Bass, 1984) 7-8.

5 See, for example, Janet Rifkin, Jonathan Millen and Sara Cobb, 'Toward a New Discourse for Mediation: A Critique of Neutrality' (1991) 9 Mediation Quarterly 151; Rachael Field and Jonathan Crowe, 'The Construction of Rationality in Australian Family Dispute Resolution: A Feminist Analysis' (2007) 27 Australian Feminist Law Journal 97; Jonathan Crowe and Rachael Field, 'The Problem of Legitimacy in Mediation' (2008) 9(1) Contemporary Issues in Law 48; Susan Armstrong, 'Recognition and Relationality with Families and Children from Minority Cultural and Faith Backgrounds in Australian Family Dispute Resolution' (2015) 29 Australian Journal of Family Law 203; Boulle and Field, Mediation in Australia, 58-60.

6 Boulle and Field, Mediation in Australia, 40-1.

7 See, for example, Bernard Mayer, 'The Dynamics of Power in Mediation and Negotiation' (1987) 16 Mediation Quarterly 75; Tony F Marshall, 'The Power of Mediation' (1990) 8 Mediation Quarterly 115; Michael A McCormick, 'Confronting Social Injustice as a Mediator' (1997) 15 Mediation Quarterly 293.

8 See, for example, Boulle and Field, Australian Dispute Resolution, chs 1 and 13; Boulle and Field, Mediation in Australia, ch 8; Rachael Field, 'A Mediation Profession in Australia: An Improved Framework for Mediation Ethics' (2007) 18 Australasian Dispute Resolution Journal 1. 
communal standards of conduct. ${ }^{9}$ The idea of mediation as a profession therefore requires the mediation community to be able to articulate its core ethical standards, and for those standards to be capable of enactment in practice. What, then, comes after neutrality and impartiality? ${ }^{10}$ Can the conceptualisation of these terms be modified in response to the above concerns - or should an entirely new ethical paradigm be developed to provide a more contemporary foundation for mediation practice?

This book offers a response to these questions, developing a new theory of mediation ethics that emphasises the nature of mediation as a relational process. We argue that the focus of mediation ethics should move away from the untenable notions of mediator neutrality and impartiality and towards the premise that the core and non-negotiable function of the mediator is to support the parties to achieve self-determination. We supplement this focus with a view of mediation ethics as emerging dynamically from the efforts of mediators to respond to the unique needs and interests of the parties, in the process of assisting each of the parties to achieve what we term 'relational party self-determination' through guided communication with each other. This new paradigm provides the basis for a picture of the mediation community as a community of practice with its own internal standards of excellence, as well as a more sophisticated ethical framework for mediation practice. We build on this theory to present a vision of what it means to think about mediation as a profession involving high-level expertise and practically effective professional standards.

\section{THE NEED FOR A NEW PARADIGM}

Our case for a new ethical paradigm is not purely theoretical. Rather, it is grounded in the realities and demands of mediation practice. We contend that a traditional ethic of neutrality or impartiality is not only theoretically unsound, but also unrealistic because it does not help mediators understand or negotiate the kinds of ethical dilemmas that frequently arise in practice. The following three case studies illustrate the kinds of scenarios mediators may face where neutrality or impartiality may be at odds with the needs and interests of the parties.

Tuan and Oanh: Tuan is a 65-year-old man living in an assisted care facility. He suffers from early-onset dementia. He is in dispute with his 38-year-old daughter,

9 Randy Hodson and Teresa A Sullivan, The Social Organization of Work (Wadsworth, 5th ed, 2012) ch 11; Shapira, A Theory of Mediators 'Ethics, 5-6.

10 Bernard Mayer asked this question more than 15 years ago in Beyond Neutrality: Confronting the Crisis in Conflict Resolution. 
Oanh, about the sale of the family home. Tuan often appears confused and struggles to articulate his concerns. He sometimes goes off on unrelated tangents and seems to forget why he is there. Oanh, who is a lawyer, presents her case articulately and persuasively, including making reference to the legal position.

Maha and Tony: Maha runs a small furniture upholstery business from his home. Tony placed a substantial order with him for upholstery for a boat. However, when the order was delivered, Tony refused to pay the agreed price, citing minor flaws in the work. Tony is represented by his lawyer, Phil, who refuses to budge from their initial lowball offer. Maha is a recent immigrant who speaks little English. He appears intimidated and overwhelmed by the process. The mediator is concerned he will accept the offer on the table simply in order to end the dispute.

Josh and Lauren: Josh and Lauren have recently separated after an eight-year marriage. They have two young children and are in dispute over parenting issues. Josh is very assertive and prone to long, aggrieved speeches. Lauren barely speaks. When she does speak, Josh often talks over her, even though the mediator reminds him not to do so. Lauren seems afraid to assert herself in Josh's presence. The mediator suspects there is a history of domestic and family violence, although neither party has disclosed this.

These three scenarios all pose challenges that are far from uncommon in mediation practice. Each of them involves some kind of power imbalance between the parties. In the first case, Tuan's ability to participate in the mediation is affected by his age and health, while Oanh is well equipped to articulate her interests by virtue of her legal training. In the second case, there are cultural and linguistic issues to be addressed in ensuring that Maha can engage fully in the process, while Tony's legal representation poses the challenge of avoiding overly positional negotiations. In the third case, the dynamics of the mediation may need to be carefully managed in order to safeguard Lauren's safety, as well as to enable her to appropriately articulate and assert her interests and those of her children.

There is a range of tools available to mediators in confronting these kinds of challenges. These might involve helping the parties obtain support or advice from medical practitioners, social workers, cultural support workers, interpreters or legal professionals. They might also involve techniques such as active listening, curious questioning, agenda setting, reframing and separate sessions. However, exhorting the mediator to be neutral or impartial tells them little about when and how these tools and techniques should be deployed; indeed, it may be at odds with the demands of best practice. A mediator who actively manages the process to ensure that both parties have the chance to articulate their needs and interests cannot truly be described as neutral, in the sense of being detached and disinterested in the dispute and its outcome. Nor does it help to insist that the mediator must be impartial, in the sense of being 
even-handed and objective. Rather, what is required for mediators to address these kinds of scenarios is active and targeted intervention in the process that takes account of the distinctive needs and positions of the parties. The ethical role of the mediator is to advance party self-determination by managing the process in a professionally appropriate way. This may or may not involve being neutral or impartial.

In arguing for a new paradigm of mediation ethics in which neutrality or impartiality is no longer central, we are not suggesting that mediators should act unfairly or in a biased fashion. Rather, our position is that the achievement of party self-determination requires an ethic of responsiveness to the parties' needs and interests that may involve both neutral and non-neutral (or impartial and non-impartial) actions and interventions. For example, in a mediation involving parties who have a history of domestic and family violence, the achievement of relational party self-determination may ethically require the mediator, at different times throughout the process, to actively respond to and support the parties in different, party-specific ways. A further example concerns parties who, due to their experience of the conflict between them, are both having difficulties creatively generating options. In this situation, the attainment of relational party self-determination might ethically require a mediator to engage more actively in generating suggestions or options for the parties' consideration and assessment. This may mean, depending on the context, that the mediator takes distinct and individually specific approaches to assisting the parties, rather than treating them identically or behaving in a purely detached or objective way.

As the analysis in the following chapters of the book further explains, if acting in a neutral or impartial fashion does not result in the support of party self-determination, then, ethically, the mediator should not be neutral or impartial. The place of neutrality and impartiality is untenable in such circumstances. This does not mean that the value of neutral and impartial conduct on the part of the mediator is jettisoned altogether. However, in the new ethical paradigm we propose, neutrality and impartiality are simply approaches that may be harnessed as part of a mediator's ethical decision-making about process management in support of party self-determination. Relational self-determination becomes the overarching goal.

\section{THE PLAN OF THE BOOK}

Our case for a new paradigm of mediation ethics proceeds as follows. Chapter 2 introduces the foundational paradigm of mediation practice, discussing the most commonly employed models of mediation (facilitative, transformative, evaluative and narrative) and the extent to which they require mediator neutrality and/or impartiality. We contend that the positioning of the facilitative 
model as the paradigmatic example of mediation has entrenched mediator neutrality and party self-determination as the core principles of mediation ethics. Chapter 3 builds on this analysis by offering an overview of the historical development of codes of mediator conduct in Western legal systems, showing how the facilitative model of mediation, with its ideals of neutrality and party self-determination, serves as an implicit yardstick for mediation practice.

Chapter 4 then discusses the traditional ideals of neutrality and party self-determination in more detail, examining how these notions have been understood as intertwined in approaches to mediation ethics to date. We argue that, although the concepts are traditionally seen as mutually supporting, there are some unresolved tensions between them. Chapter 5 draws these tensions out in more detail by critically examining the notion of mediator neutrality and its role in the traditional ethical paradigm. We contend that the dominant conception of mediator ethics is both theoretically unstable and at odds with the realities of mediation practice. The demands of neutrality place mediators in a position where they are unable to respond dynamically and realistically to the needs of individual parties to enable party self-determination without stepping outside the ethical boundaries of their role.

Chapter 6 then turns to the concept of mediator impartiality, which has been adopted as an alternative to the traditional notion of neutrality in some jurisdictions. We argue that mediator impartiality either draws its content from traditional notions of mediator neutrality, in which case it confronts the same problems that we outline in Chapter 5, or it fails to provide the substantive content needed to help mediators resolve ethical dilemmas in practice. In either case, the notion of mediator impartiality is effectively empty and provides no solution to the dilemmas associated with mediator neutrality. Chapter 7 further problematises existing approaches to mediation ethics by considering the ways in which the relative informality of mediation may disadvantage inexperienced or vulnerable participants by requiring them to negotiate within an unfamiliar model of discourse. This provides the springboard for the new model of mediation ethics outlined in the final chapters.

Chapter 8 lays the groundwork for our rethinking of mediation ethics by advancing a conception of mediators as a professional community of practice. We argue that mediation ethics is best understood as an evolving body of standards emerging by a process of consensus and dialogue, rather than a set of rules imposed on mediators from above. Chapter 9 then introduces a new framework for mediation ethics that abandons the traditional emphasis on neutrality and impartiality in favour of a focus on what we term relational party self-determination: that is, mutual self-determination for the parties achieved in relationship with each other. The primary role of party self-determination in this new framework is supported by a focus on informed consent and an ethos of professionalism in mediation practice. 
Chapter 10 further operationalises our proposed new ethical framework by offering a series of ethical guidelines that mediators can use to apply the framework in their practice. We argue for a contextual and relational conception of mediation ethics that is not rule oriented, but encourages mediators to form appropriate, considered and justifiable judgments in response to ethical challenges. The key feature of mediation, on this view, is not that the mediator is neutral or impartial, but rather that the parties are supported to achieve genuinely self-determined outcomes through mutual engagement in the process. This approach to ethical decision-making offers a more tenable foundation for mediation ethics into the future. 